\title{
Dr. HUGHLINGS JACKSON'S PRINCIPLES OF CEREBRAL PATHOLOGY.
}

\author{
By Prof. Dr. OTTO SITTIG (Prague).
}

The hundredth anniversary of Dr. Hughlings Jackson's birth is honoured by all our profession this year. We cannot, I think, honour the memory of a great man better than by endeavouring to understand his ideas. And this is the more necessary in the case of Dr. Jackson's scientific work, as, curiously enough, comparatively few of his views have become common medical property. Among most practitioners Dr. Hughlings Jackson's name is probably known only by the term " Jacksonian epilepsy."

How has it come to pass that Dr. Jackson's work has not met with the appreciation it deserved? Sir Henry Head has tried to answer this question, and offers four reasons for the extraordinary neglect of Dr. Jackson's work. First, his modesty; he published his papers in journals accessible only with difficulty to the general reader. Secondly, his style. Thirdly, the nomenclature he adopted from Herbert Spencer. Fourthly, the nature of his ideas was foreign to the current views of the day. To the difficulty of Dr. Jackson's style may be added the fact that the matter he deals with is itself extremely difficult. But the main reason for the neglect of his views is, in my opinion, something more than all these considerations. It is, I think, that Dr. Jackson has never given a systematic account of his views. They are scattered all over his numerous papers, and only he who tries to formulate the whole system of Dr. Jackson's theories realizes the great difficulty of this task. But this system is precisely what best reveals Dr. Jackson's greatness. If asked what Dr. Jackson's great scientific achievement was, I should reply that he was the only one who tried to build up a system of nervous pathophysiology - and physiology-on the basis of clinical facts. Dr. Jackson tells us himself that the task he set himself in the study of nervous diseases was to discover general laws or principles.

Before discussing these principles I should like to make some prelıminary remarks. Dr. Jackson was an adherent of the hypothesis of concommittance, or, as it is more commonly called now, psycho-physical parallelism; not, however, as a metaphysical solution of the problem of the relation between body and mind, but as a convenient hypothesis. Consequently, in pursuing this principle of concommittance, Dr. Jackson postulates with emphasis the strict separation of psychology and physiology. Dr. Jackson does not, of course, deny the great importance of psychology, but for him as a physiologist, psychology is not the end, but a means to the end. Dr. Jackson tells us clearly how he wishes psychology to be applied to the study of the pathology of the nervous system. Psychical symptoms are for Dr. Jackson only signs of what is going wrong in the nervous system. For this purpose, Dr. Jackson says, we must reduce the complex, often psychical, symptoms to simple physiological elements, e.g., movements. Then we shall discover general principles. I have used for this method of investigation the metaphor of translation from one language into another, from the language of psychology into that of physiology, and Dr. Jackson himself makes such an 
allusion in one place, saying: "With regard to all crude sensations, we can-since, although abnormal, they are psychical states-only translate what the patient tells us into physical conditions."

Dr. Jackson says the function of the nervous system is to store up and give out energy. The brain consists of nervous arrangements representing sensori-motor processes, or the nervous system represents parts of the body. Here we have to explain, I think, the term "represent." I have the impression that Dr. Jackson himself felt this difficulty, as is shown by his trying to give an explicit definition of the word "represent." He says it does not here mean representation as a borough is represented in parliament; but "a higher centre represents a lower one" means that the higher centre is the lower one raised to a higher power. But even this explanation seems to me not quite clear, in fact, too metaphorical. I have not found in Dr. Jackson's writings the explanation that I consider to be the only applicable one. I think the expression: "a part of the brain represents a certain part of the body" means, and can mean, nothing else but that that part of the body is connected with that part of the brain by nervous substance. But this connection is not always a direct and simple one. The higher the nervous centre in the nervous system, the more indirect, the more complex and intricate, becomes the connection. So we understand what Dr. Jackson means by saying that there is no special faculty of co-ordination, but that co-ordination is the same as representation and is the function of the nervous system. In other words, he says, there is no centre of co-ordination, but every nervous centre co-ordinates or, which is the same, represents movements and impressions of different parts of the body.

Dr. Jackson holds all nervous activity to be a mode of reflex action. Here he follows an opinion of his teacher, Dr. Laycock. The difference is only that in the lower centres reflex activity is perfect, i.e., the motor reaction upon an impression occurs without delay and is inevitable. The higher, however, the centre, the more imperfect is the reflex activity, i.e., the reaction either gets delayed, or need not necessarily follow the impression. Dr. Jackson expresses this in still another way: the anatomical unit is a sensori-motor process; it is not an afferent (sensory) process only, nor a motor process only, but these two put in a particular relation by cells of grey matter. The anatomical unit represents, either directly or indirectly, a peripheral impression associated with a muscular adjustment.

Now, as to general principles, we can distinguish between physiological and pathological ones, and we shall begin with the former.

There is the principle of evolution. Evolution is a passage from the simple, the most automatic, towards the complex, the most voluntary or least automatic. The highest centres, the anatomical substrata of consciousness, are most complex and least automatic.

Another important principle that Dr. Jackson stated, but gave no name to, I might call the principle of unity. Dr. Jackson says that just as any state of consciousness is a state of a whole person psychical, so the correlative activity is 
of nervous arrangements representing a whole person physical (the whole organism). The highest centres, the substrata of consciousness, are therefore, as Dr. Jackson says, unifying centres.

And now we shall deal with Dr. Jackson's principles of nervous pathology.

The first principle is that of dissolution. Dissolution is the reverse of the process of evolution. From the explanation, given above, of the process of evolution it logically follows that dissolution is a passage from the most complex, the least automatic, towards the most simple, the most automatic. Or, in other words, in disease those parts suffer first and most, which have the highest, the most complex, the most varied functions, or those functions that have developed latest.

A consequence of this principle is that in recovery the simplest and the most automatic functions recover first. One may call this the principle of re-evolution.

Dr. Jackson distinguishes between uniform and local, and between total and partial, dissolution. Total dissolution is equivalent to death. Therefore, we are interested most in partial dissolution. Dr. Jackson thinks of evolution as being in levels of different degree of evolution. The term "level" is used, as Dr. Jackson emphasizes, metaphorically. In disease some levels only are affected-the highest; whereas others, the lower ones, remain active. Therefore, to undergo partial dissolution is equivalent to being reduced to a lower level of evolution. Hence in dissolution we must consider two parts of the nervous system: the part destroyed by disease, or at least put out of action, and the level of evolution remaining, the still acting part of the nervous system. With the former goes loss of function, negative symptoms; with the latter go positive symptoms. This principle of negative and positive symptoms, as one might call it, is most important, and disregard of it leads to serious errors.

This principle of positive and negative symptoms is closely connected with another general principle of nervous pathology: the principle of loss of control, as Dr. Jackson used to call it ("release" is the usual term nowadays). Dr. Jackson says that with increasing evolution, more and more special functions are "added on." But this " adding on" is at the same time a "keeping down" of the lower functions. The higher centres, which have evolved out of the lower ones, inhibit the action of these lower centres. In disease dissolution is not only a "taking off" of the higher, but at the same time a "letting go" of the lower. So it comes about that, the higher levels being put out of action, the activity of the lower centres is increased.

Dr. Jackson studied, moreover, the conditions of dissolution and of loss of control associated with it. He lists four factors:-(I) Depth of dissolution. The shallower the dissolution, the higher the level of evolution remaining, and the more complex the positive symptoms present. The deeper the dissolution, the lower the level of evolution remaining, and the simpler, the more automatic, the positive symptoms present. (2) The second factor is the personality of the patient, whether 
old or young, whether educated or uneducated, whether intelligent or unintelligent. (3) The third factor is the rapidity with which dissolution takes place, or, which is the same, with which control is removed. The more suddenly dissolution occurs, the more increased is the activity of the lower level of evolution remaining, and vice versa. (4) The fourth factor is the influence of external circumstances and loçal bodily states.

The next principle of nervous pathology is that of compensation. In order to understand it, we must explain Dr. Jackson's views on localization. Dr. Jackson is, as he has often emphasized, not an adherent of "abrupt" localization. He is, he says, neither universalizer nor localizer. He holds that every part of the brain-especially of the highest centres-represents the whole organism, but a certain part of it particularly. He infers this structure of the nervous system from two facts. He distinguishes two kinds of lesions, destroying and discharging lesions. A part of the brain can be destroyed without any striking symptoms, but discharge of even a small part of the brain can produce general convulsions. These are the two facts from which Dr. Jackson argues the above-mentioned structure of the nervous system. A centre being destroyed, compensation takes place; for the remaining centres, which represent every part of the body too, compensate the loss of function. But, Dr. Jackson adds, some defect remains; some very special, very intricate defect will persist, because the parts of the body are not represented in any other centre in the same arrangement, in the same sequence, etc., as in the one destroyed. This fact is expressed by Dr. Jackson by the statement that compensation is never complete. A centre being discharged, all the parts of the body represented in it are put into activity. Dr. Jackson? calls this principle "co-operation in excess"; it is, so to speak, inverted compensation.

We have now to mention a principle that Dr. Jackson considered to be of great importance. He calls it the principle of compound order. It has not met with much attention, but it seems to me very interesting. It is best explained by the facts from which Dr. Jackson derived it. If a hemiplegia increases, the paralysis does not increase in depth only, but also in extension; the paralysis not only deepens in the parts already affected, but also extends to parts not previously affected. On the other hand, in the course of an epileptiform seizure the convulsion not only increases in the parts first affected, but also extends to other parts. In fact, for dissolution in general this principle of compound order holds good. Ist depth of dissolution: h, i.e., the highest level alone is affected; and depth: $h_{2}+m$, i.e., the highest level is more affected, and the middle slightly; 3rd depth: $h_{3}+m_{2}+1$, i.e., the highest level is still more affected, the middle less, and the lowest least. Dr. Jackson supposes that the principle of compound order is analogous to Weber's law.

I have tried to give a survey of the whole system of nervous pathophysiology that Dr. Jackson put forward. But this short account is far from sufficient to give a true idea of what his work really contains. His papers are full of precise observations and of philosophical views. What gives Dr. Jackson's work such a high standard is that it is pervaded throughout by a true philosophic spirit. 